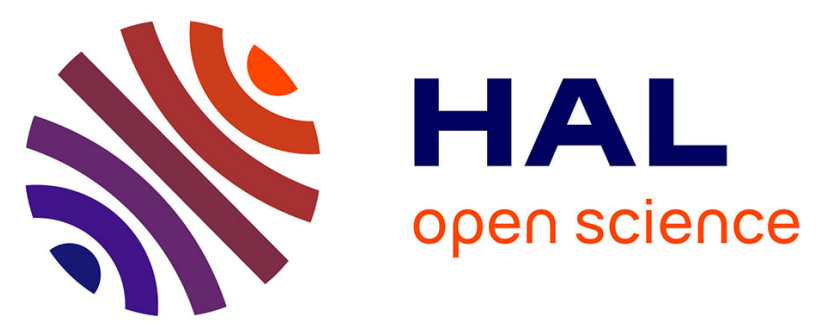

\title{
Synthesis of Robust MOFs@COFs Porous Hybrid Materials via an Aza-Diels-Alder Reaction: Towards High-Performance Supercapacitor Materials
}

Haijun Peng, Jesus Raya, Fanny Richard, Walid Baaziz, Ioan-Ovidiu Ersen, Artur Ciesielski, Paolo Samori

\section{To cite this version:}

Haijun Peng, Jesus Raya, Fanny Richard, Walid Baaziz, Ioan-Ovidiu Ersen, et al.. Synthesis of Robust MOFs@COFs Porous Hybrid Materials via an Aza-Diels-Alder Reaction: Towards High-Performance Supercapacitor Materials. Angewandte Chemie International Edition, 2020, 10.1002/anie.202008408 . hal-03020591

\section{HAL Id: hal-03020591 https://hal.science/hal-03020591}

Submitted on 23 Nov 2020

HAL is a multi-disciplinary open access archive for the deposit and dissemination of scientific research documents, whether they are published or not. The documents may come from teaching and research institutions in France or abroad, or from public or private research centers.
L'archive ouverte pluridisciplinaire HAL, est destinée au dépôt et à la diffusion de documents scientifiques de niveau recherche, publiés ou non, émanant des établissements d'enseignement et de recherche français ou étrangers, des laboratoires publics ou privés. 


\title{
Synthesis of robust MOFs@COFs porous hybrid materials via
}

\section{aza-Diels-Alder reaction: towards \\ high performance} supercapacitor materials

\author{
Haijun Peng, ${ }^{[a]}$ Jésus Raya ${ }^{[b]}$ Fanny Richard, ${ }^{[a]}$ Walid Baaziz, ${ }^{[c]}$ Ovidiu Ersen, ${ }^{[c]}$ Artur Ciesielski ${ }^{*[a]}$ and \\ Paolo Samori ${ }^{\star[a]}$
}

\begin{abstract}
Metal-organic frameworks (MOFs) and covalent organic frameworks (COFs) attracted enormous attention in recent years. Recently, MOF@COF are emerging as hybrid architectures combining the unique features of the individual components to enable the generation of materials displaying novel physicochemical properties. Herein we report an unprecedented use of aza-Diels-Alder cycloaddition reaction as postsynthetic modification of MOF@COFLZU1, to generate aza-MOFs@COFs hybrid porous materials with extended $\pi$-delocalization. A a proof-of-concept, the obtained azaMOFs@COFs is used as electrode in supercapacitors displaying specific capacitance of $20.35 \mu \mathrm{F} \mathrm{cm}$ and high volumetric energy density of $1.16 \mathrm{~F} \mathrm{~cm}^{-3}$. Our approach of postsynthetic modification of MOFs@COFs hybrids implement rational design for the synthesis of functional porous materials and expands the plethora of promising application of MOFs@COFs hybrid porous materials in energy storage applications.
\end{abstract}

\section{Introduction}

Over the past decade, the colossal research effort devoted to porous materials has paved the way towards a vast number of applications, with a direct impact on our daily life. Functional porous materials including metal-organic frameworks (MOFs) and covalent organic frameworks (COFs) can be produced through large-scale industrial processes and display tailored-made properties. MOFs are typically formed by coordination of metal ions or clusters with organic ligands, which act as linkers. ${ }^{[1]}$ Bivalent or trivalent aromatic carboxylic acids or $\mathrm{N}$-containing aromatics are commonly used to form frameworks with zirconium, zinc, copper, aluminium, chromium, and other elements. ${ }^{[2]}$ Owing to their tuneable structure and functional nature, high porosity and

[a] H.-J. Peng, Dr. F. Richard, Dr. A. Ciesielski, Prof. P. Samorì Université de Strasbourg, CNRS, ISIS

8 alleé Gaspard Monge, 67000 Strasbourg, France ciesielski@unistra.fr, samori@unistra.fr

[b] Dr. J. Raya

Membrane Biophysics and NMR, Institute of Chemistry, UMR 7177

Université de Strasbourg, Membrane Biophysics and NMR,

1 Rue Blaise Pascal, F-67000 Strasbourg, France.

[c] Dr. W. Baaziz, Prof. O. Ersen

Université de Strasbourg, CNRS, IPCMS UMR 7504

23 rue du Loess, F-67034 Strasbourg, France.

Supporting information for this article is given via a link at the end of the document. large internal surface area, MOFs has been widely used in gas storage and separation, ${ }^{[3]}$ catalysis, ${ }^{[4]}$ sensors, ${ }^{[5]}$ drug delivery. ${ }^{[6]}$ Noteworthy, the applications of MOFs in energy storage system have recently emerged. ${ }^{[7]}$ Unfortunately, the widespread use of MOFs as energy storage materials, including their use as electrodes in supercapacitors, is hampered by their poor stability combined with their low specific capacitance as a result of their limited conductivity. Following the seminal work of Diaz et al. on MOF Co8-MOF-5 as electrodes in supercapacitors with a relatively low gravimetric capacitance of $2 \mathrm{~F} \mathrm{~g}^{-1},{ }^{18]}$ numerous other MOF-based supercapacitors have been reported. ${ }^{[9]}$ In order to enhance MOF capacitance as supercapacitors electrode, MOFs have been incorporated into conductive materials, such as graphene ${ }^{[10]}$ and conductive polymers. ${ }^{[11]}$ Yaghi et al. reported a series of different nanocrystal MOFs/graphene hybrids incorporated into solid-state supercapacitor devices, finding a zirconium MOF exceptional high areal capacitance of $5.09 \mathrm{mF} \mathrm{cm}^{-}$ $2[12]$

On the other hand, COFs exhibit much higher thermal and chemical stability due to the all-covalent nature of the architecture in which the small molecular units are held together by strong covalent bonds, such as $\mathrm{B}-\mathrm{O}, \mathrm{C}=\mathrm{N}, \mathrm{B}-\mathrm{N}, \mathrm{C}=\mathrm{C}$ and $\mathrm{B}-\mathrm{O}-\mathrm{Si}^{[13]}$. The great variety and programmability of covalent bonds between the COF's building units, which can be obtained by exploiting various synthetic organic reactions, enables chemical engineering of COFs' surface areas, pore sizes and crystal structure forming $2 \mathrm{D}$ or 3D crystalline functional architectures. ${ }^{[14]}$

More recently, MOFs@COFs hybrid structures have been developed as a new type of multifunctional porous materials by introducing the as-prepared MOF into the synthetic process of COF. Such materials contain the structural traits and combine the advantages of individual components thereby yielding highest performances in gas separation, ${ }^{[15]}$ (photo-)catalysis, ${ }^{[16]}$ aptasensors $^{[17]}$ and lithium storage ${ }^{[18]}$. Thus far, the growth of MOFs@COFs hybrid materials has primarily relied on the use of the imine bond $(-\mathrm{C}=\mathrm{N}-)$ formation, through the condensation of unreacted $-\mathrm{NH}_{2}$ groups of MOFs with aldehydes used for the synthesis of Schiff-base COFs. For example, Fu et al. reported the first class of COF@MOF (COF-300@ZIF-8) composite membranes, which displayed higher separation selectivity of $\mathrm{H}_{2} / \mathrm{CO}_{2}$ gas mixtures compared to the individual COF and MOF membranes. ${ }^{[19]}$ Moreover, hybrid core-shell MOFs@COFs composites, such as $\mathrm{NH}_{2}$-MIL-68-MOF@TPA-COF, ${ }^{[20]} \mathrm{NH}_{2}$-MIL125@COF-LZU1, ${ }^{[21]} \quad \mathrm{NH}_{2}$-Uio-66/Tppa-1-COF ${ }^{[22]}$ and Uio-66$\mathrm{NH}_{2} @$ COF-TAPB-BTCA ${ }^{[23]}$ have been synthesized and have been successfully used in (photo-)catalysis. However, except for 
such Mn-MOF@COF hybrid reported by Wang et al.., ${ }^{[18]}$ the use of MOFs @ COFs hybrid materials in energy storage applications remains largely unexplored.

Supercapacitor energy storage devices gained considerable attention due to their cost-effectiveness, eco-friendly nature, high power density, moderate energy density and longterm cycle stability. These qualities make supercapacitors key devices to power portable electronics. ${ }^{[24]}$ Although a vast number of electrode materials have been reported to date, carbon nanomaterials attracted great attention due to their tuneable physicochemical and electrochemical properties. In particular, activated carbons and metal oxides were successfully employed to increase the overall performance of supercapacitors. However, their irregular morphologies, wide pore size distributions and low energy density cannot keep pace with increasingly higher energy storage requirements. ${ }^{[25]}$ On the other hand, three-dimensional architectures have attracted notable attention for supercapacitor applications because of their low density, highly accessible surface area, structural interconnectivity (micro-, meso- and macro-interconnected pores). Therefore, the use of porous scaffolds such as MOFs and COFs can take advantage of the specific surface area, presence of the pores with controllable size and effective charge transport. Yet, the aforementioned drawbacks of those materials have to be solved. A key strategy for overcoming the problem of low energy density relies on the use of new synthetic paths or postsynthetic modification of MOFs@COFs hybrid porous materials towards improved electrochemical electrodes for supercapacitors.

Here, we report the synthesis of MOF@COF followed by aza-Diels-Alder cycloaddition to form aza-MOF@COF hybrid electrode for supercapacitors with enhanced specific capacitance of $20.35 \mu \mathrm{F} \mathrm{cm}{ }^{-2}$. The as-prepared electrode exhibited high durability and excellent capacitance retention $89.3 \%$ after 2000 cycles. Moreover, the use of molecular spacers provided high volumetric energy density of $1.16 \mathrm{~F} \mathrm{~cm}^{-3}$. The improvement of electrochemical performance, including the rate capacity and durability, is the result of our simple postsynthetic modification, highlighting the general relevance of our approach.

\section{Results and Discussion}

The synthesis of aza-MOF@COF is accomplished following the strategy illustrated in Figure 1 (see the Supporting Information for the experimental details). $\left[\mathrm{Zr}_{6} \mathrm{O}_{4}(\mathrm{OH})_{4}(\mathrm{ATA})_{12}\right]$ (ATA:2aminoterephthalate), named MOF-Uio-66- $\mathrm{NH}_{2}$ hereafter was synthesised according to the previously reported protocol, ${ }^{[26]}$ with slight modification being the use of polyvinylprrolidone (PVP) as a surfactant, to improve the dispersibility of MOF-Uio-66- $\mathrm{NH}_{2}$ and facilitate an effective heterogeneous nucleation of the coating imine-linked COF. An imine-linked COF-LZU1 ${ }^{[27]}$ was chosen to construct the core-shell material given its dynamic covalent nature arising from the presence of imine bonds inside the COF, that can be latter converted into ultrastable crystalline porous aromatic frameworks. ${ }^{[28]}$ The aza-MOF@COF porous hybrid material was synthesised in three steps. The first step relies onsurface condensation of the MOF-Uio-66- $\mathrm{NH}_{2}$ with 1,3,5benzenetricarboxaldehyde (BTCA) yielding MOF-Uio-66(CHO). In the second step the COF layer has been grown on MOF-Uio66 MOF by employing the condensation between the aldehydes present on the surface of the as-prepared MOF-Uio-66(CHO) and $p$-phenylenediamine. In the third and final step, the postsynthetic modification of MOF@COF-LZU1 has been accomplished by making use of aza-Diels-Alder reaction to obtain aza-MOF@COF hybrid structure. In particular, aza-Diels-Alder reaction between aryl imine of MOF@COF-LZU1 and phenylacetylene resulted in successful conversion of the MOF@COF-LZU1 imine bridges into corresponding quinoline-linked aza-MOF@COF.
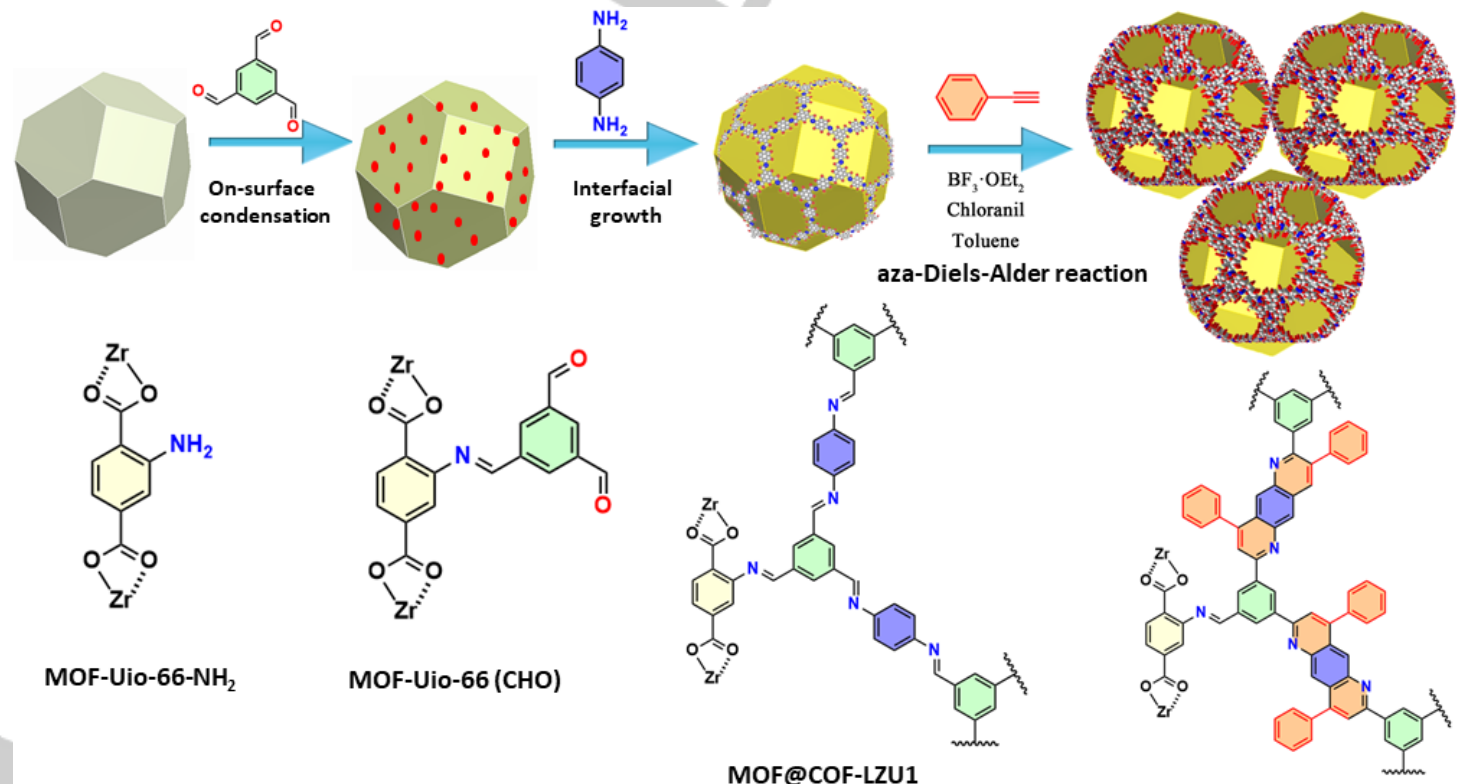

MOF@COF-LZU1 
The structure of the MOF-Uio-66- $\mathrm{NH}_{2}$ was investigated by powder X-ray diffraction (PXRD) analysis and Fourier transform infrared (FT-IR) spectroscopy (Figure S1 and S2). The patterns of as-synthesised MOF-Uio-66- $\mathrm{NH}_{2}$ is in good accordance with previously reported results, ${ }^{[22]}$ highlighting that the use of PVP does not influence the reaction itself, yet, it improves the dispersibility of MOF-Uio-66- $\mathrm{NH}_{2}$. The successful growth of COFLZU1 onto MOF-Uio-66- $\mathrm{NH}_{2}$ and corresponding conversion into quinoline-linked aza-MOF@COF upon addition of phenylacetylene into MOF@COF-LZU1 hybrid materials were characterized by several analytical methods. The comparison of FT-IR spectra of aza-MOF@COF with MOF-Uio-66- $\mathrm{NH}_{2}$ and MOF@COF-LZU1 (Figure S3) revealed a presence of new broad cluster of peaks at $\sim 1600 \mathrm{~cm}^{-1}$. Within this cluster, characteristic peaks at 1541 and $1580 \mathrm{~cm}^{-1}$ can be identified and ascribed to the formation of quinolyl species. ${ }^{[29]}$ Moreover, the blue shift of the C$\mathrm{C}=\mathrm{N}-\mathrm{C}$ stretch from 1232 to $1256 \mathrm{~cm}^{-1}$ provides unambiguous evidence for the formation of aromatic quinoline core after the reaction. ${ }^{[30]}$ Aza-Diels-Alder reaction between aryl imines and arylalkynes allows the conversion of COF-LZU1 imine linkers in MOF@COF-LZU1 into corresponding quinoline-linked azaMOF@COF.

Solid-state NMR structural analysis of such materials are usually obtained on the basis of classical mono-dimensional ${ }^{1} \mathrm{H}$ to ${ }^{13} \mathrm{C}$ cross-polarization magic-angle spinning experiments
$(\mathrm{CP} / \mathrm{MAS})^{[31]}$ and discussions rely exclusively on isotropic chemical shifts measurements that provides structural information at nucleus level. Unlike in solution, and despite improved sample crystallinity, the ${ }^{13} \mathrm{C}$ resonances are rather broad in the solid-state and easily overlap. Such features may render assignments of signals difficult, leading in turn to misinterpretation, in particular in the case of MOFs and COFs in which quaternary and $\mathrm{CH}$ chemical shifts are piled up in the same small crowded zone (ca 110 to $160 \mathrm{ppm}$ ). In order to circumvent this potential problem, we performed more advanced experiments including ${ }^{13} \mathrm{C}$ spectral edition, ${ }^{[32]}{ }^{1} \mathrm{H}$ Ultra-Fast MAS Direct Polarisation $\left({ }^{1} \mathrm{H}\right.$ DP/MAS) and ${ }^{1} \mathrm{H} /{ }^{13} \mathrm{C}$ frequency shifted Lee-Goldburg HETCOR $\left({ }^{1} \mathrm{H} /{ }^{13} \mathrm{C}\right.$ FSLG HETCOR). ${ }^{[33]}$ The latter allows to detect spatial proximities between ${ }^{1} \mathrm{H}$ and ${ }^{13} \mathrm{C}$ and may be tuned to select short internuclear distances like $\mathrm{CH}$ to distant quaternaries. Moreover, in addition to its enhanced resolution with respect to mono-dimensional spectra, it may separate spin-systems belonging to different molecules and proves useful when residual reagents also overlap peaks of interest (Figure S4-7). On the basis of this bundle of information complete assignments of the investigated species were possible (Figure 2) on both proton and carbon sides providing a strong evidence for reactions completion (see SI for detailed assignments proceeding). a)
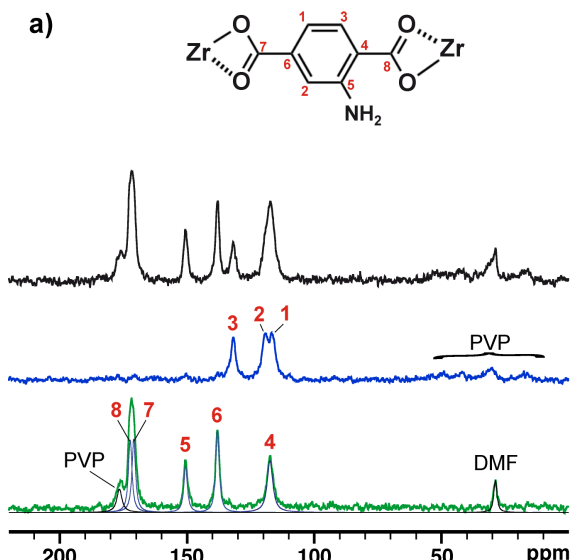<smiles>CC=Nc1cc(C2O[Z]O2)ccc1C(=O)OC</smiles>

b)
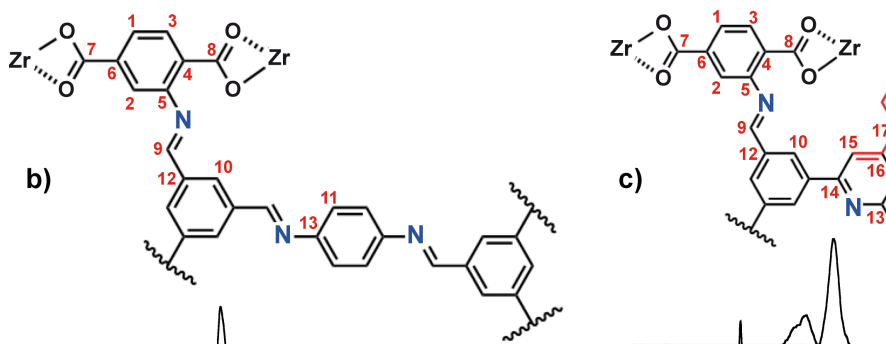

c)
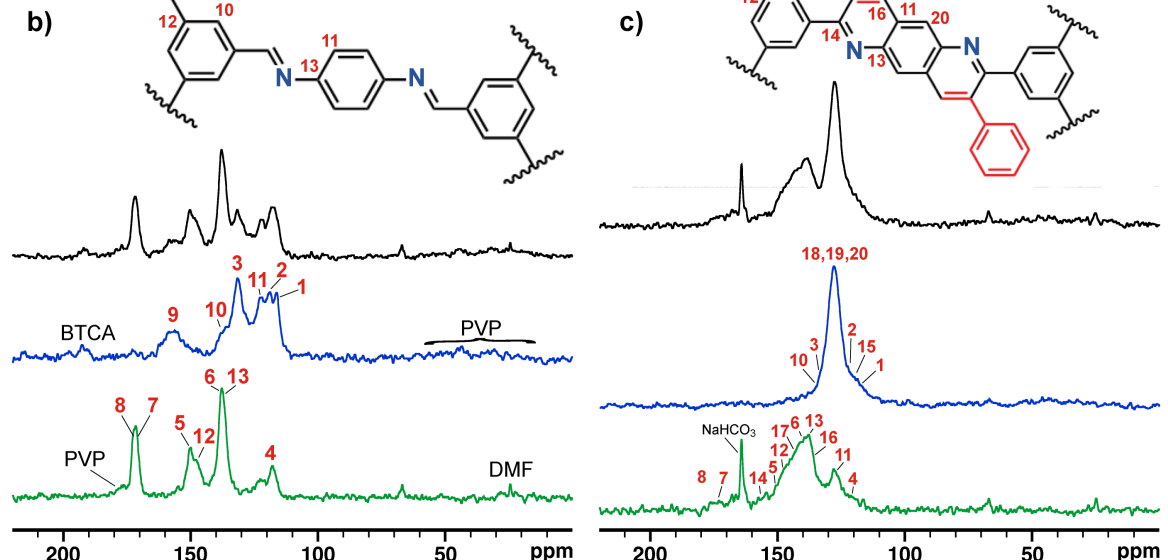

Figure 2. ${ }^{13} \mathrm{C}$ solid-state NMR series of MOF-Uio-66-NH 2 (a), MOF@COF-LZU1 (b) and aza-MOF@COF (c). Bottom (green) : Edited CP/MAS (only Cq and

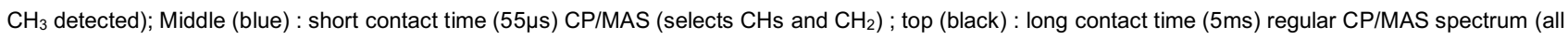
carbons there). CSA fitting of Edited CP/MAS MOF-Uio-66- $\mathrm{NH}_{2}$ (dark blue and black) in $\mathrm{Cq} / \mathrm{CH}_{3}$ spectrum to show overlapped components in carboxylic peaks, Omitted on the other traces for clarity.

An in-depth analysis of MOF-Uio-66- $\mathrm{NH}_{2}$ and COF-LZU1 substructures of MOF@COF-LZU1 indicates that the ${ }^{13} \mathrm{C}$ spectra of the latter should not differ significantly from individual ones of the neat MOF-Uio-66- $\mathrm{NH}_{2}$ and COF-LZU1. In fact, the chemical shifts are essentially due to electronic surrounding at nucleus level and only minor changes on carbon site from MOF@COFLZU1 relative to MOF-Uio-66- $\mathrm{NH}_{2}$ and COF-LZU1 can be expected, it is natural to observe no changes between spectra from MOF@COF-LZU1 versus the sum of MOF-Uio-66- $\mathrm{NH}_{2}$ and COF-LZU1 (Figure S8 and Table S1). On the other hand, ${ }^{1} \mathrm{H}$ ultra- fast MAS at speeds up to $60 \mathrm{kHz}$ can provide the resolution needed to gain more details. In MOF-Uio- $66-\mathrm{NH}_{2}{ }^{1} \mathrm{H}$ spectrum a broad and intense peak located at ca $5 \mathrm{ppm}$ is ascribed to the overlapped $\mathrm{NH}_{2}$ of MOF-Uio-66- $\mathrm{NH}_{2}$ and water. Such peak is absent in the spectra of COF-LZU1, yet, a smaller signal can be observed in MOF@COF-LZU1 at 4.8 ppm (Figure 3). Given the fact that, unlike ${ }^{13} \mathrm{C} C P / M A S,{ }^{1} \mathrm{H}$ DP/MAS spectra are quantitative, it was possible to deconvolute them in order to obtain relative intensities of each signal of interest, mainly the $\mathrm{CHs}$ and $\mathrm{NH}_{2} / \mathrm{H}_{2} \mathrm{O}$. When in MOF-Uio-66- $\mathrm{NH}_{2}$ the $\mathrm{NH}_{2} / \mathrm{H}_{2} \mathrm{O}$ signal integrates to 7.8 
for $3 \mathrm{CHs}$ in MOF@COF-LZU1 it gives 5.8 for the same $3 \mathrm{CHs}$ in its MOF-Uio-66- $\mathrm{NH}_{2}$ sub-spectrum. Within the experimental error, it can be seen that the $\mathrm{NH}_{2}$ of MOF-Uio-66- $\mathrm{NH}_{2}$ have nearly completely disappeared and thus been quite totally converted to $\mathrm{C}-\mathrm{N}=\mathrm{C}$. Hence, the remaining peak at $4.8 \mathrm{ppm}$ may be ascribed solely to water. Finally, the imine to quinoline conversion in azaMOF@COF is clearly evidenced in Figure 4, in which no evident signal is detected within the $150-160 \mathrm{ppm}$ range in the $\mathrm{CH}$-edited ${ }^{13} \mathrm{C}$ spectrum. Signals reappear in the $\mathrm{Cq} / \mathrm{CH}_{3}$ edited spectrum, clearly showing efficient transformation of $\mathrm{C}=\mathrm{N}$ imine $(\mathrm{CH}$ at 157 ppm) into 2-quinolyl carbon (also 157 ppm). Noteworthy, some residual signal in the baseline of $\mathrm{Cq} / \mathrm{CH}_{3}$ edited spectrum is indicative of very low amount of residual imine $(-\mathrm{C}=\mathrm{N})$.

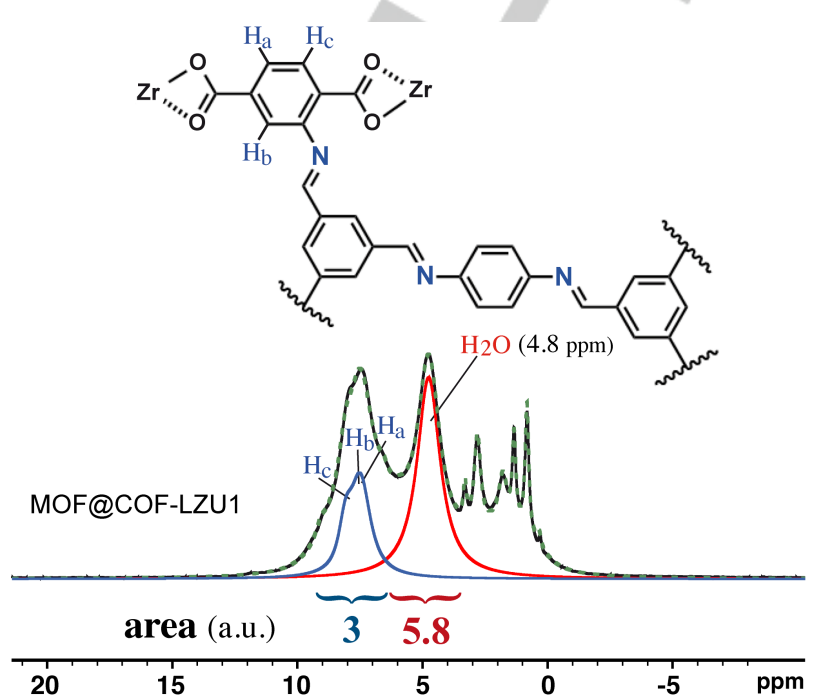

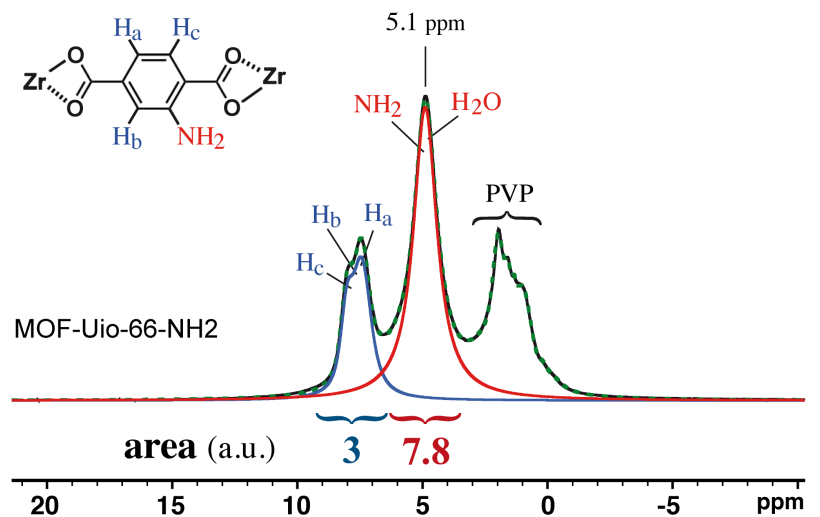

Figure 3. Ultra-Fast MAS $1 \mathrm{H}$ NMR of MOF-Uio-66- $\mathrm{NH}_{2}$ (left) and MOF@COF-LZU1 (right). For the sake of clarity only $\mathrm{CHs}$ and $\mathrm{NH}_{2} / \mathrm{H}_{2} \mathrm{O}$ components are shown. Black: experimental, dotted green: calculated spectrum, blue: sum of fitted $\mathrm{CHs}$, red: $\mathrm{H}_{2} \mathrm{O}+\mathrm{NH}_{2}$ or $\mathrm{H}_{2} \mathrm{O}$. Difference in areas correspond to the loss of 2 protons when passing from MOF-Uio-66- $\mathrm{NH}_{2}$ to MOF@COF-LZU1, indicating total conversion of $\mathrm{NH}_{2}$ in imine bridge. $\mathrm{CH}$ Chemical shifts were not fitted as they were got directly from ${ }^{1} \mathrm{H} /{ }^{13} \mathrm{C} 2 \mathrm{D}$ experiments (see $\mathrm{SI}$ ).

To gain more insights into the nature of nitrogen species in azaMOF@COF and the conversion from imine to quinoline, the electronic state of the $\mathrm{N}$ element was studied by the X-ray photoelectron spectroscope (XPS). The analysis of N1s spectra of MOF-Uio-66- $\mathrm{NH}_{2}$ revealed the presence of a peak at $399.5 \mathrm{eV}$ corresponding to the primary amine species. As previously observed, a negligible peak at $401.6 \mathrm{eV}$ can be assigned to $-\mathrm{NH}$ groups of the organic linkers in pure UiO-66- $\mathrm{NH}_{2}$ nanocrystals (Figure 5a). ${ }^{[16 a, 34]}$ When compared to pristine MOF-Uio-66- $\mathrm{NH}_{2}$, MOF@COF-LZU1 only shows a binding energy at $399.2 \mathrm{eV}$, indicating the formation of imine bonds(Figure 5b). Upon postsynthetic modification, a fraction of the N1s is shifted to higher binding energies $\sim 399.7 \mathrm{eV}$, corresponding to the $\mathrm{C}=\mathrm{N}$ in quinoline moieties (Figure 5c). ${ }^{[35]}$ Interestingly, Figure $\mathrm{S9}$ displays the C1s XPS spectra of aza- MOF@COF compared to MOF-Uio-66- $\mathrm{NH}_{2}$ and MOF@COF-LZU1. It reveals an apparent $\pi-\Pi^{*}$ satellite peak, which results from the extended delocalized $\pi$ electrons induced by the phenylacetylene aromatic ring. ${ }^{[36]}$

The morphologies of the as-synthesized MOF-Uio-66- $\mathrm{NH}_{2}$, MOF@COF-LZU1 and aza-MOF@COF were assessed by fieldemission scanning electron microscopy (FS-SEM) and highresolution transmission electron microscope (HR-TEM). MOFUio-66- $\mathrm{NH}_{2}$ nanoparticles shown in Figure 6 exhibit octahedral shape with smooth surface and an average size of $\sim 200 \mathrm{~nm}$. After the surface modification with COF, the MOF@COF-LZU1 nanoparticles maintain their general morphology with an increased averaged size up to $\sim 220 \mathrm{~nm}$ as shown in Figure $6 \mathrm{~d}$. Noteworthy, after postsynthetic modification the surface of azaMOF@COF nanoparticles becomes more rough on their surface and a further slight increase in size has been monitored $(\sim 230$ $\mathrm{nm}$, Figure 6g). The HR-TEM images of MOF@COF-LZU1 nanoparticles illustrated in Figure $6 f$ reveals the presence of a layer lattice for COF-LZU1 at the edge of pristine MOF-Uio-66$\mathrm{NH}_{2}$ which was estimated around $20 \mathrm{~nm}$, being consistent with the increased nanoparticle average size. It is worth mentioning that after the surface postsynthetic modification with aza-Diels-Alder

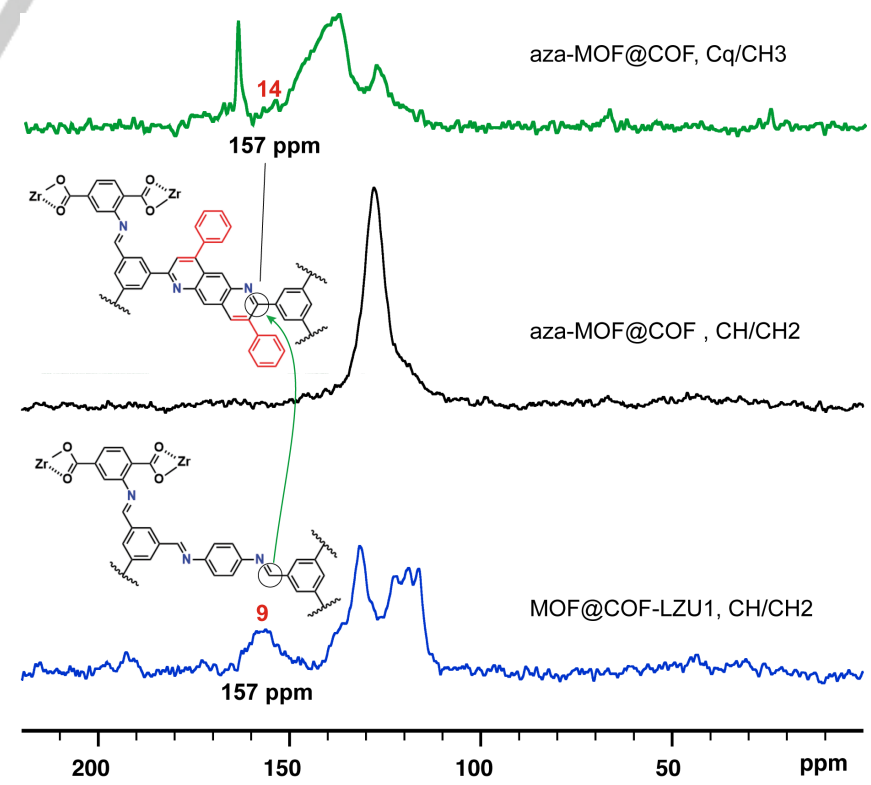

Figure 4. Bottom (blue): $\mathrm{CH} / \mathrm{CH}_{2}$ selected ${ }^{13} \mathrm{C}$ CP/MAS NMR spectrum of MOF@COF-LZU1, with focus on imine CH located at 157 ppm (see fig. 2 for labelling). Middle (black): aza-MOF-COF $\mathrm{CH} / \mathrm{CH}_{2}$ selective ${ }^{13} \mathrm{C} \mathrm{CP} / \mathrm{MAS}$ spectrum, where no more imine $\mathrm{CH}$ is present. Top (green): aza-MOF-COF $\mathrm{Cq} / \mathrm{CH}_{3}$ selective ${ }^{13} \mathrm{C}$ CP/MAS spectrum. 2-quinolyl carbon signal at $157 \mathrm{ppm}$ is detected. 
reaction, the aza-MOF@COF nanoparticles display apparent drawbacks in the COF-LZU1 lattice layer and a relative thin and
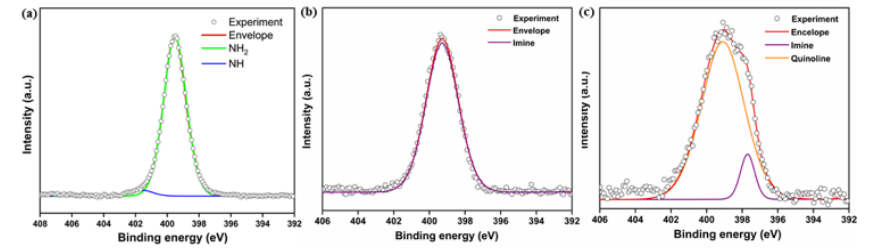

Figure 5. The N1s XPS spectra of a) MOF-Uio-66-NH2, b) MOF@COFLZU1, c) aza-MOF@COF.

(a)

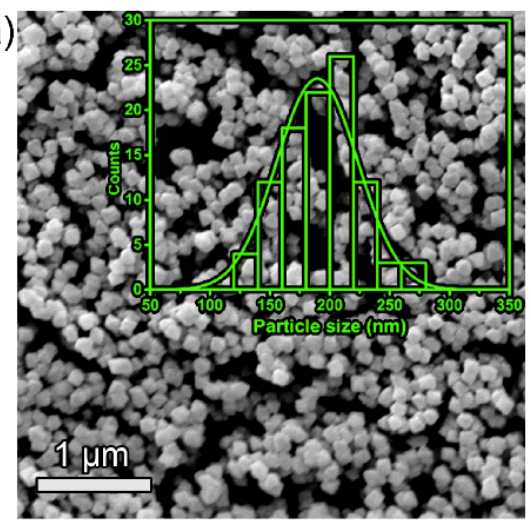

(d)

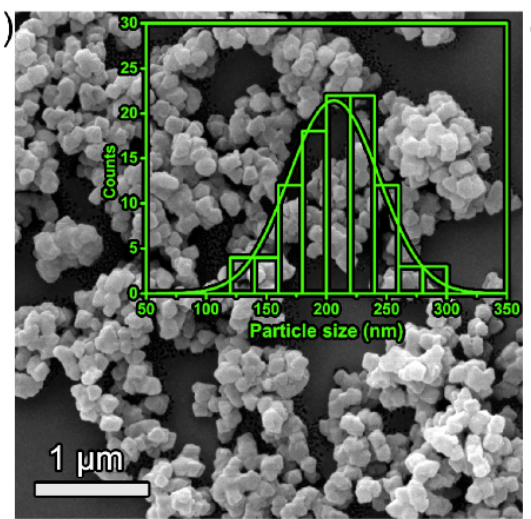

(g)

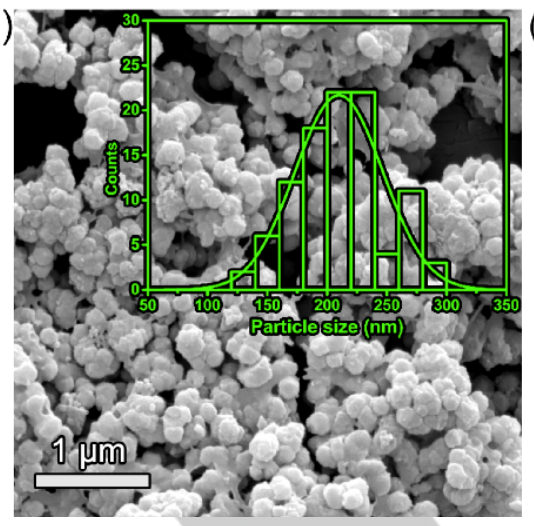

(b)

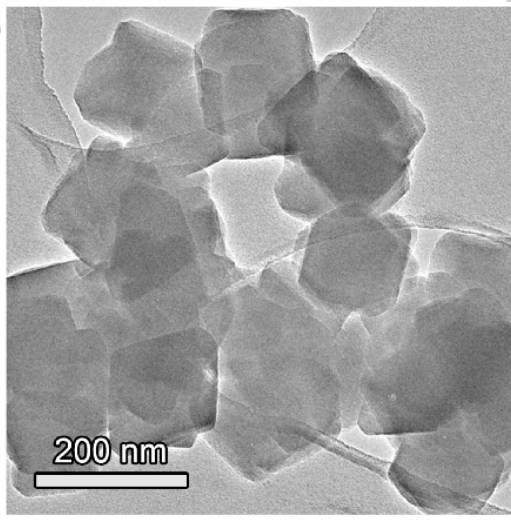

(e)

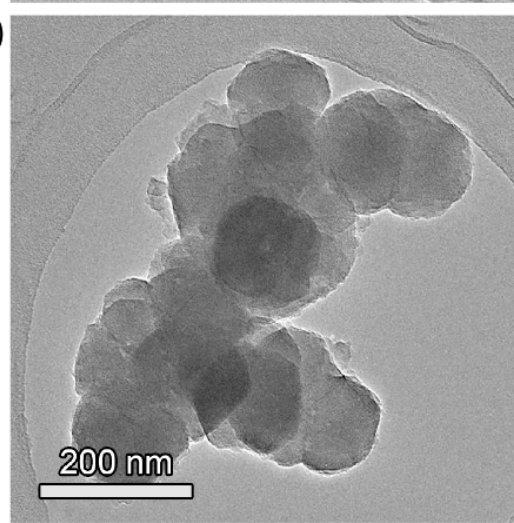

(h)

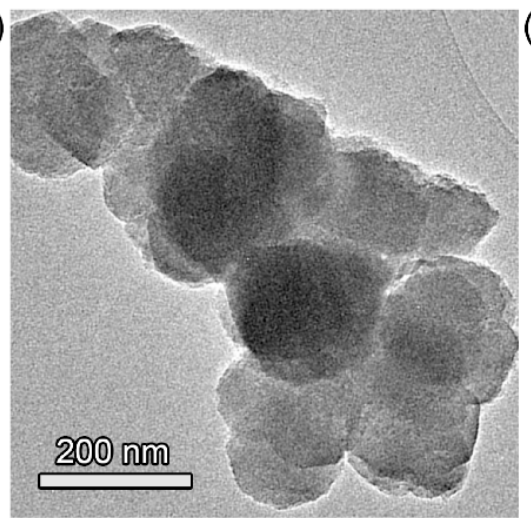

(c)

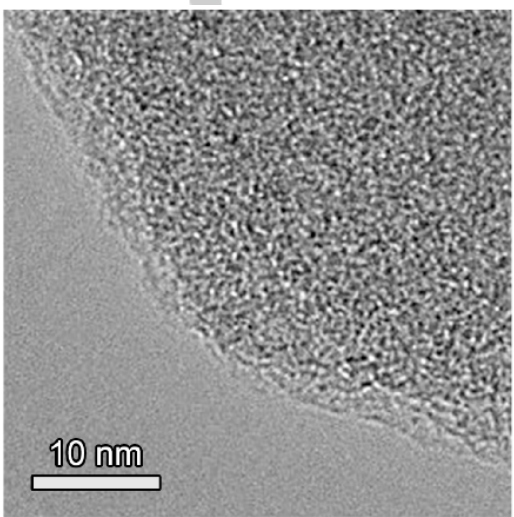

(f)

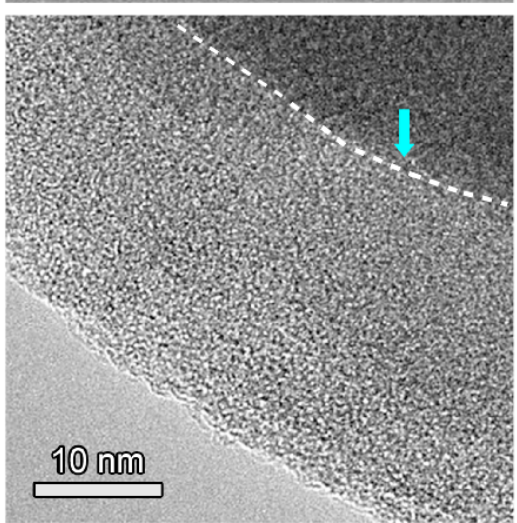

(i)

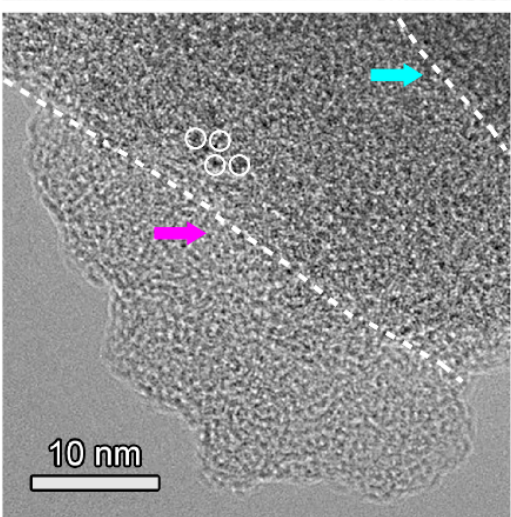

Figure 6. The SEM images (insert is particle size distribution), TEM and HR-TEM of a-c) MOF-Uio-66-NH2, d-f) MOF@COF-LZU1and g-i) aza-MOF@COF

MOF-Uio-66-NH2, MOF@COF-LZU1 and aza-MOF@COF based electrodes were constructed into a coin-shaped cell capacitor and soaked with $1 \mathrm{M}$ solution of tetraethylammonium tetrafluoroborate $\left(\left(\mathrm{C}_{2} \mathrm{H}_{5}\right)_{4} \mathrm{NBF}_{4}\right)$ in acetonitrile. After the coinshaped cell was sealed, cyclic voltammetry (CV) was measured in a relatively wide scan range from 10 to $1000 \mathrm{mv} \mathrm{s}^{-1}$ with the 
potential values swept in a range of the cut-off values $(0 \leq E \leq 2.7$ $\mathrm{V})$, which is typically used to calculate the capacitance performance (including the role played by a pair of active materials and substrate, and separator ${ }^{[37]}$ (Figure 7 a-c).

The CV curves of aza-MOF@COF based electrode display a more rectangular shape and higher current values compared with MOF-Uio66- $\mathrm{NH}_{2}$ and MOF@COF-LZU1, confirming the improved electrochemical stability and capacitance. ${ }^{[38]}$ Specific capacitance calculated from the $\mathrm{CV}$ curves at different scan rates and charge/discharge profiles in Figure S14-16 was used to evaluate the charge storage capacity of the supercapacitors. The areal capacitance of MOF-Uio-66-NH2, MOF@COF-LZU1 and azaMOF@COF were estimated as 7.89, 9.56 and $20.35 \mathrm{mF} \mathrm{cm}$ areal $^{-2}$, respectively (Figure $7 \mathrm{~d}$ ). The corresponding stack capacitance were calculated as $0.45,0.55$ and $1.16 \mathrm{~F} \mathrm{~cm}_{\text {stack }^{-3}}$, respectively. The measured capacitance of aza-MOF@COF is twice as high as that of pristine MOF-Uio66- $\mathrm{NH}_{2}$ and MOF@COF-LZU1 materials. Noteworthy, such capacitance is over 11 and 17 times higher than those of activated carbon $\left(0.788 \mathrm{mF} \mathrm{cmareal}^{-2}\right.$ and $0.100 \mathrm{~F} \mathrm{~cm}_{\text {stack }}$ ${ }^{3}$ ) and graphene $\left(0.515 \mathrm{mF} \mathrm{cmareal}{ }^{-2}\right.$ and $\left.0.065 \mathrm{~F} \mathrm{~cm}_{\text {stack }^{-3}}\right)$, and much higher than some previously reported systems (Tables S2). Furthermore, the aza-MOF@COF cell exhibits good cycling stability with a capacitance retention of $89.3 \%$ compared with MOF-Uio-66- $\mathrm{NH}_{2}$ (69.5\%) and MOF@COF-LZU1 (73.9\%) after 2000 cycles performed at a current density of $0.2 \mathrm{~A} \mathrm{~cm}^{-2}$ (Figure $7 \mathrm{e})$. The excellent supercapacitor performances of aza-
MOF@COF is attributed to the extended m-delocalization in the hybrid structure and decreased pore size (from $\sim 1 \mathrm{~nm}$ to $\sim 0.7 \mathrm{~nm}$ ) which is closer to the electrolyte ions (the diameter of $\left(\mathrm{C}_{2} \mathrm{H}_{5}\right)_{4}{ }^{+}$and $\mathrm{NBF}_{4}{ }^{-}$ions in electrolyte is 0.68 and $0.33 \mathrm{~nm}$, respectively ${ }^{[39]}$ ) and result anomalous increase in supercapacitor devices. ${ }^{[39-40]}$ To get more insight into the anomalous capacitance increase, electrochemical impedance spectroscopy (EIS) was carried out between $10^{-1}$ and $10^{6} \mathrm{~Hz}$ to evaluate the internal resistances for the charge transfer process of the samples. As show in Figure 7f, a relatively small semicircle in the high frequency region represents the dominant resistive nature of the supercapacitor system consisting of electrode/electrolyte/current-collector. The beginning of the semicircle line represents the resistance (Rs) of the electrolyte in contact with the current collector and electrode materials, the termination of the semicircle line represents the internal resistance $(\mathrm{Rp})$ of the electrode materials. The diameter of the semicircle (Rp-Rs) is equal to the equivalent series resistance (ESR), the calculation results for MOF-Uio-66- $\mathrm{NH}_{2}$, MOF@COF-LZU1 and aza-MOF@COF are 6.85, 6.39 and 4.84 $\Omega \mathrm{cm}^{-1}$, respectively. The ESR results confirm that the postsynthetic modification of MOF@COF-LZU1 results in increased electrical conductivity. Moreover, the second segment of the aza-MOF@COF EIS curves display a steeper slope which highlights increased ion permeation into the electrode material with respect to MOF-Uio-66-NH2, MOF@COF-LZU1. (a)

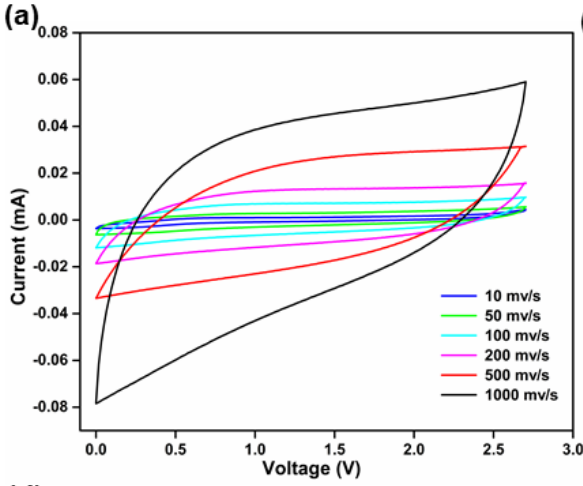

(d)

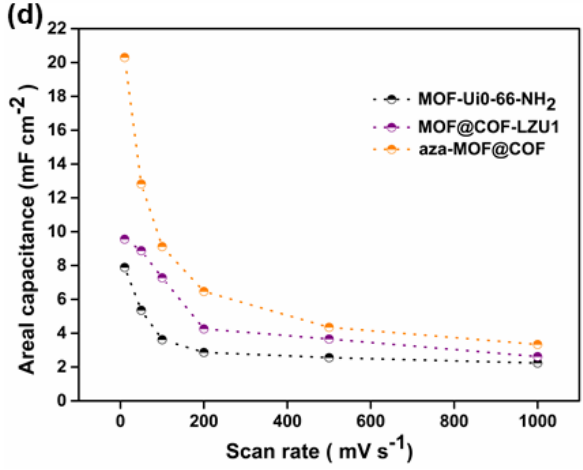

(b)

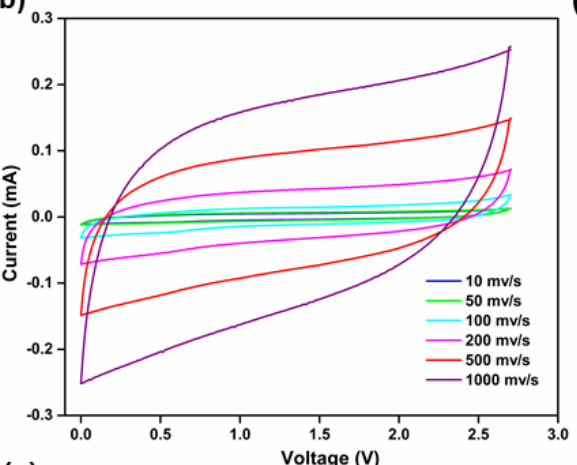

(e)

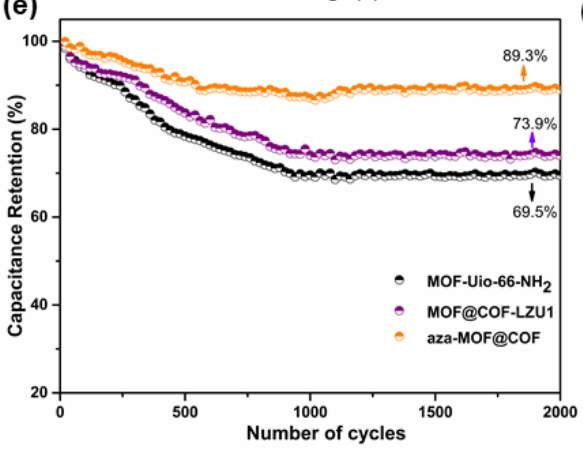

(c)

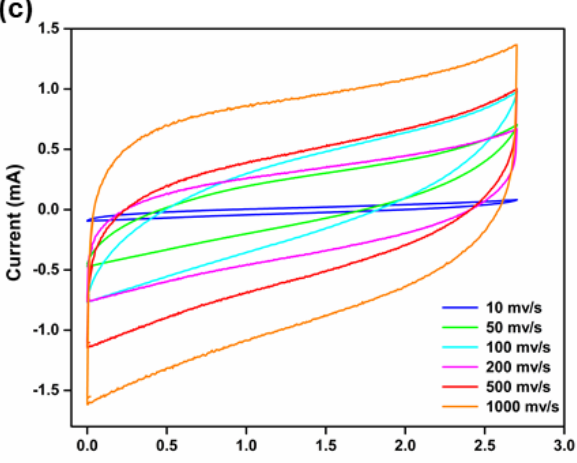

(f)

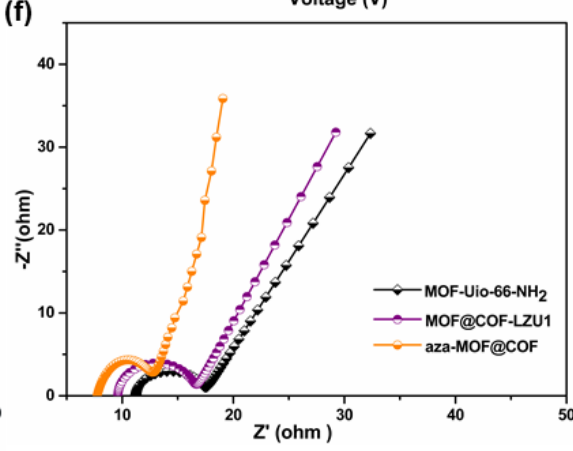

Figure 7. Cyclic voltammetry curve of a) MOF-Uio-66- $\mathrm{NH}_{2}$, b) MOF@COF-LZU1, c) aza-MOF@COF, d) areal capacitance, e) capacitance retention, f) Nyquist electrochemical impedance spectra.

\section{Conclusions}

In summary, we have synthesised a new functional porous materials aza-MOF@COF by introducing quinoline moieties via postsynthetic modification employing aza-Diels-Alder cycloaddition into imine-linked MOF@COF hybrid porous materials. The obtained aza-MOF@COF hybrid not only retains highly crystalline nature and porosity, but also displays superior capacitor performance in energy storage system thanks to its high robustness. As a proof-of-concept application in supercapacitor 
devices, the aza-MOF@COF device exhibits a high specific capacitance of $20.35 \mu \mathrm{F} \mathrm{cm}^{-2}$ and an exceptional stack capacitance of $1.16 \mathrm{~F} \mathrm{~cm}^{-3}$, which exceeds most of the previously reported state-of-the-art MOFs@COFs hybrid materials. Our approach of postsynthetic modification of MOFs@COFs hybrids implement rational design for the synthesis of robust, functional porous materials and expands the plethora of promising application of MOFs@COFs hybrid porous materials in energy storage applications.

\section{Acknowledgements}

We acknowledge funding from the European Commission through the Marie Sklodowska-Curie project ULTIMATE (GA813036), the Agence Nationale de la Recherche through the Labex projects CSC (ANR-10-LABX-0026 CSC) and NIE (ANR11-LABX-0058 NIE) within the Investissement d'Avenir program (ANR-10-120 IDEX-0002-02), the International Center for Frontier Research in Chemistry (icFRC) as well as the Chinese Scholarship Council and the "111" Project (Grant No. B17020).

Keywords: functional porous materials $\cdot$ metal-organic framework $\cdot$ covalent organic framework $\cdot$ aza-Diels-Alder reaction• supercapacitor

[1] a) H.-C. Zhou, J. R. Long, O. M. Yaghi, Chem. Rev. 2012, 112, 673-674 b) N. Stock, S. Biswas, Chem. Rev. 2012, 112, 933-969; c) M. Y. Masoomi, A Morsali, A. Dhakshinamoorthy, H. Garcia, Angew. Chem. Int. Ed. 2019, 58, 15188-15205.

[2] a) S.-M. Zhang, Z. Chang, T.-L. Hu, X.-H. Bu, Inorg. Chem. 2010, 49, 11581-11586; b) A. Dhakshinamoorthy, H. Garcia, Chem. Soc. Rev. 2014, 43, 5750-5765; c) P. Li, N. A. Vermeulen, X. Gong, C. D. Malliakas, J. F. Stoddart J. T. Hupp, O. K. Farha, Angew. Chem. Int. Ed. 2016, 55, 10358-10362.

[3] a) T. Rodenas, I. Luz, G. Prieto, B. Seoane, H. Miro, A. Corma, F. Kapteijn, I. X. F. X. Llabres, J. Gascon, Nat. Mater. 2015, 14, 48-55; b) C. Zhang, B. H. Wu, M. Q. Ma, Z. Wang, Z. K. Xu, Chem. Soc. Rev. 2019, 48, 3811-3841 [4] a) S. Y. Ding, J. Gao, Q. Wang, Y. Zhang, W. G. Song, C. Y. Su, W. Wang, J. Am. Chem. Soc. 2011, 133, 19816-19822; b) H. W. Liang, X. Zhuang, S. Bruller, X. Feng, K. Müllen, Nat. Commun. 2014, 5, 4973.

[5] O. Yassine, O. Shekhah, A. H. Assen, Y. Belmabkhout, K. N. Salama, M. Eddaoudi, Angew. Chem. Int. Ed. 2016, 55, 15879-15883.

[6] a) P. Horcajada, T. Chalati, C. Serre, B. Gillet, C. Sebrie, T. Baati, J. F. Eubank, D. Heurtaux, P. Clayette, C. Kreuz, J.-S. Chang, Y. K. Hwang, V. Marsaud, P.-N. Bories, L. Cynober, S. Gil, G. Férey, P. Couvreur, R. Gref, Nat. Mater. 2010, 9, 172-178; b) P. Horcajada, C. Serre, M. Vallet-Regí, M. Sebban, F. Taulelle, G. Férey, Angew. Chem. Int. Ed. 2006, 45, 5974-5978.

[7] a) S. Wei, S. Xu, A. Agrawral, S. Choudhury, Y. Lu, Z. Tu, L. Ma, L. A Archer, Nat. Commun. 2016, 7, 11722; b) H.-J. Peng, G.-X. Hao, Z.-H. Chu, J. Lin, X.-M. Lin, Y.-P. Cai, Cryst. Growth Des. 2017, 17, 5881-5886; c) S. E. Jerng B. Chang, H. Shin, H. Kim, T. Lee, K. Char, J. W. Choi, ACS Appl. Mater. Interfaces 2020, 12, 10597-10606; d) Y. Hu, N. Goodeal, Y. Chen, A. M. Ganose, R. G. Palgrave, H. Bronstein, M. O. Blunt, Chem Comm 2016, 52, 9941-9944; f) D. Sheberla, J. C. Bachman, J. S. Elias, C.-J. Sun, Y. Shao-Horn, M. Dincă, Nat. Mater. 2016, 16, 220-224

[8] R. Díaz, M. G. Orcajo, J. A. Botas, G. Calleja, J. Palma, Mater. Lett. 2012 68, 126-128.

[9] a) S.-L. Li, Q. Xu, Energy Environ. Sci. 2013, 6, 1656-1683; b) L. Wang, Y. Han, X. Feng, J. Zhou, P. Qi, B. Wang, Coord Chem. Rev. 2016, 307, 361381; c) H. Wang, Q.-L. Zhu, R. Zou, Q. Xu, Chem 2017, 2, 52-80.

[10] a) C. Petit, T. J. Bandosz, Adv. Mater. 2009, 21, 4753-4757; b) C. Qu, L. Zhang, W. Meng, Z. Liang, B. Zhu, D. Dang, S. Dai, B. Zhao, H. Tabassum, S. Gao, H. Zhang, W. Guo, R. Zhao, X. Huang, M. Liu, R. Zou, J. Mater. Chem. A 2018, 6, 4003-4012.

[11] a) C. Lu, T. Ben, S. Xu, S. Qiu, Angew. Chem. Int. Ed. 2014, 53, 6454 6458 ; b) M. Kalaj, K. C. Bentz, S. Ayala, J. M. Palomba, K. S. Barcus, Y. Katayama, S. M. Cohen, Chem. Rev. 2020.

[12] K. M. Choi, H. M. Jeong, J. H. Park, Y.-B. Zhang, J. K. Kang, O. M. Yaghi, ACS Nano 2014, 8, 7451-7457.

[13] a) E. Jin, J. Li, K. Geng, Q. Jiang, H. Xu, Q. Xu, D. Jiang, Nat. Commun. 2018, 9, 4143; b) S. S. Han, J. L. Mendoza-Cortés, W. A. Goddard lii, Chem.
Soc. Rev. 2009, 38, 1460-1476; c) P. J. Waller, F. Gándara, O. M. Yaghi, Acc. Chem. Res. 2015, 48, 3053-3063; d) K. Geng, T. He, R. Liu, S. Dalapati, K. T. Tan, Z. Li, S. Tao, Y. Gong, Q. Jiang, D. Jiang, Chem. Rev. 2020.

[14] S.-Y. Ding, W. Wang, Chem. Soc. Rev. 2013, 42, 548-568.

[15] a) J. Fu, S. Das, G. Xing, T. Ben, V. Valtchev, S. Qiu, J. Am. Chem. Soc. 2016, 138, 7673-7680; b) Y. Cheng, Y. Ying, L. Zhai, G. Liu, J. Dong, Y. Wang M. P. Christopher, S. Long, Y. Wang, D. Zhao, J. Membr. Sci. 2019, 573, 97106.

[16] a) D. Sun, S. Jang, S.-J. Yim, L. Ye, D.-P. Kim, Adv. Funct. Mater. 2018 28, 1707110; b) F.-M. Zhang, J.-L. Sheng, Z.-D. Yang, X.-J. Sun, H.-L. Tang, M. Lu, H. Dong, F.-C. Shen, J. Liu, Y.-Q. Lan, Angew. Chem. Int. Ed. 2018, 57, 12106-12110; c) M. Cai, Y. Li, Q. Liu, Z. Xue, H. Wang, Y. Fan, K. Zhu, Z. Ke, C.-Y. Su, G. Li, Adv. Sci. 2019, 6, 1802365.

[17] N. Zhou, Y. Ma, B. Hu, L. He, S. Wang, Z. Zhang, S. Lu, Biosens. Bioelectron. 2019, 127, 92-100.

[18] W. Sun, X. Tang, Q. Yang, Y. Xu, F. Wu, S. Guo, Y. Zhang, M. Wu, Y. Wang, Adv. Mater. 2019, 31, 1903176.

[19] J. Fu, S. Das, G. Xing, T. Ben, V. Valtchev, S. Qiu, J. Am. Chem. Soc. 2016, 138, 7673-7680.

[20] Y. Peng, M. Zhao, B. Chen, Z. Zhang, Y. Huang, F. Dai, Z. Lai, X. Cui, C. Tan, H. Zhang, Adv. Mater. 2018, 30, 1705454.

[21] D. Sun, S. Jang, S.-J. Yim, L. Ye, D.-P. Kim, Adv. Funct. Mater. 2018 28,1707110

[22] F.-M. Zhang, J.-L. Sheng, Z.-D. Yang, X.-J. Sun, H.-L. Tang, M. Lu, H. Dong, F.-C. Shen, J. Liu, Y.-Q. Lan, Angew. Chem. Int. Ed. 2018, 57, 1210612110.

[23] L. Garzon-Tovar, J. Perez-Carvajal, A. Yazdi, J. Hernandez-Munoz, P. Tarazona, I. Imaz, F. Zamora, D. Maspoch, Angew. Chem. Int. Ed. 2019, 58, 9512-9516.

$[24] \quad$ a) Y. Wang, Y. Song, Y. Xia, Chem. Soc. Rev. 2016, 45, 5925-5950; b) V. Augustyn, P. Simon, B. Dunn, Energy Environ. Sci. 2014, 7, 1597-1614; c) M. R. Lukatskaya, B. Dunn, Y Gogotsi, Nat Commun 2016, 7 , 12647; d) F. Bonaccorso, L. Colombo, G. Yu, M. Stoller, V. Tozzini, A. C. Ferrari, R. S. Ruoff, V. Pellegrini, Science 2015, 347, 1246501

[25] a) L. L. Zhang, X. S. Zhao, Chem. Soc. Rev. 2009, 38, 2520-2531; b) R. R. Salunkhe, Y. V. Kaneti, Y. Yamauchi, ACS Nano 2017, 11, 5293-5308.

[26] C. Gomes Silva, I. Luz, F. X. Llabrés i Xamena, A. Corma, H. García, Chem. Eur. J. 2010, 16, 11133-11138.

[27] S.-Y. Ding, J. Gao, Q. Wang, Y. Zhang, W.-G. Song, C.-Y. Su, W. Wang, J. Am. Chem. Soc. 2011, 133, 19816-19822.

[28] X. Li, C. Zhang, S. Cai, X. Lei, V. Altoe, F. Hong, J. J. Urban, J. Ciston E. M. Chan, Y. Liu, Nat. Commun. 2018, 9, 2998.

[29] N. Shindoh, H. Tokuyama, Y. Takemoto, K. Takasu, J. Org. Chem. 2008 $73,7451-7456$

[30] D. J. Dibble, M. J. Umerani, A. Mazaheripour, Y. S. Park, J. W. Ziller, A A Gorodetsky, Macromolecules 2015, 48, 557-561.

[31] a) X.-T. Li, J. Zou, T.-H. Wang, H.-C. Ma, G.-J. Chen, Y.-B. Dong, J. Am Chem. Soc. 2020, 142, 6521-6526; b) C. E. Meyet, C. H. Larsen, J. Org. Chem 2014, 79, 9835-9841; c) F.-M. Zhang, J.-L. Sheng, Z.-D. Yang, X.-J. Sun, H.-L. Tang, M. Lu, H. Dong, F.-C. Shen, J. Liu, Y.-Q. Lan, Angew. Chem. Int. Ed. 2018, 57, 12106-12110.

[32] X. L. Wu, K. W. Zilm, J. Magn. Reson. A. 1993, 102, 205-213.

[33] a) Y. Le Brech, L. Delmotte, J. Raya, N. Brosse, R. Gadiou, A. Dufour Anal. Chem. 2015, 87, 843-847; b) G. Ortiz, G. Chaplais, J.-L. Paillaud, H. Nouali, J. Patarin, J. Raya, C. Marichal, J. Phys. Chem. C 2014, 118, 22021 22029; c) B.-J. v. Rossum, H. Förster, H. J. M. D. Groot, J. Magn. Reson. 1996 124, 516-519; d) I. A. Vacchi, C. Spinato, J. Raya, A. Bianco, C. Menard-Moyon, Nanoscale 2016, 8, 13714-13721; e) X. Y. Xue, M. Kanzaki, J. Am. Ceram. Soc 2009, 92, 2803-2830.

[34] J. Xu, S. He, H. Zhang, J. Huang, H. Lin, X. Wang, J. Long, J. Mater. Chem. A 2015, 3, 24261-24271.

[35] W. J. Gammon, O. Kraft, A. C. Reilly, B. C. Holloway, Carbon 2003, 41, 1917-1923.

[36] J. A. Gardella, S. A. Ferguson, R. L. Chin, App/ Spectrosc 1986, 40, 224232.

[37] Y. Gogotsi, P. Simon, Science 2011, 334, 917-918.

[38] a) E. Raymundo-Piñero, M. Cadek, F. Béguin, Adv. Funct. Mater. 2009 19, 1032-1039; b) X. Feng, Y. Liang, L. Zhi, A. Thomas, D. Wu, I. Lieberwirth, U. Kolb, K. Müllen, Adv. Funct. Mater. 2009, 19, 2125-2129; c) Y. Kou, Y. Xu, Z. Guo, D. Jiang, Angew. Chem. Int. Ed. 2011, 50, 8753-8757.

[39] J. Chmiola, G. Yushin, Y. Gogotsi, C. Portet, P. Simon, P. L. Taberna Science 2006, 313, 1760

[40] a) C. Largeot, C. Portet, J. Chmiola, P.-L. Taberna, Y. Gogotsi, P. Simon, J. Am. Chem. Soc. 2008, 130, 2730-2731; b) J. Segalini, E. Iwama, P.-L. Taberna, Y. Gogotsi, P. Simon, Electrochem. Commun. 2012, 15, 63-65. 